\title{
The relation between total joint arthroplasty and risk for serious cardiovascular events in patients with moderate-severe osteoarthritis: propensity score matched landmark analysis
}

\begin{abstract}
Objective To examine whether total joint arthroplasty of the hip and knee reduces the risk for serious cardiovascular events in patients with moderate-severe osteoarthritis.

Design Propensity score matched landmark analysis.

Setting Ontario, Canada.

Participants 2200 adults with hip or knee osteoarthritis aged 55 or more at recruitment (1996-98) and followed prospectively until death or 2011.

Main outcome measure Rates of serious cardiovascular events for those who received a primary total joint arthroplasty compared with those did not within an exposure period of three years after baseline assessment.

Results The propensity score matched cohort consisted of 153 matched pairs of participants with moderate-severe arthritis. Over a median follow-up period of seven years after the landmark date (start of the study), matched participants who underwent a total joint arthroplasty during the exposure period were significantly less likely than those who did not to experience a cardiovascular event (hazards ratio $0.56,95 \%$ confidence interval 0.43 to $0.74, \mathrm{P}<0.001$ ). Within seven years of the exposure period the absolute risk reduction was $12.4 \%$ (95\% confidence interval $1.7 \%$ to $23.1 \%$ ) and number needed to treat was $8(95 \%$ confidence interval 4 to 57 patients).
\end{abstract}

Conclusions Using a propensity matched landmark analysis in a population cohort with advanced hip or knee osteoarthritis, this study found a cardioprotective benefit of primary elective total joint arthroplasty.

\section{Introduction}

Cardiovascular disease is the leading cause of death worldwide. ${ }^{1}$ An estimated 17.3 million people died from cardiovascular disease in 2008, representing $30 \%$ of all global deaths that year. ${ }^{1-3}$ Several factors that exacerbate the risk of cardiovascular disease have been identified, including raised blood pressure, ${ }^{45}$ poorly controlled diabetes ${ }^{6-9}$ smoking, ${ }^{10}{ }^{11}$ high body mass index, ${ }^{12}{ }^{13}$ increased stress, ${ }^{14-16}$ use of non-steroidal inflammatory drugs (NSAIDs), ${ }^{17}$ and underlying inflammation,,${ }^{19} 20$ and recently also physical inactivity. ${ }^{21-23}$

It is estimated that at least $40 \%$ of adults aged 65 or more are physically inactive. ${ }^{24}{ }^{25} \mathrm{~A}$ frequently cited reason for restricted activity in older adults is osteoarthritis. ${ }^{26}$ Osteoarthritis is the most common arthritis, affecting $15-18 \%$ of north American adults. ${ }^{27}$ Functional limitations due to osteoarthritis have been recently shown to increase all cause mortality, mainly from cardiovascular causes. ${ }^{29}$ NSAID use ${ }^{30}$ and increased psychosocial stress $^{31-36}$ may exacerbate this risk. Thus interventions designed to reduce the symptoms associated with hip and knee osteoarthritis may also lower the risk of cardiovascular disease. 
Total joint arthroplasty is the surgical treatment recommended for moderate-severe hip or knee osteoarthritis when lifestyle changes and drug management fail to control symptoms. Total joint arthroplasty has a proved benefit for improving patients' pain, mobility, gait, quality of life, and overall function. ${ }^{37} 38$ However, the impact of primary elective total joint arthroplasty on the occurrence of cardiovascular events in people with moderate-severe osteoarthritis is unknown. We conducted a propensity score matched landmark analysis in a prospective, population based cohort with hip or knee osteoarthritis ${ }^{39}$ to compare rates of serious cardiovascular events between those who underwent primary total joint arthroplasty and those who did not within three years of their initial assessment.

\section{Methods}

\section{Study sample}

In this propensity score matched cohort study we used baseline questionnaire data from the Ontario Hip/Knee Study (1996-98), ${ }^{39}$ a population based cohort of 2411 adults aged 55 or more with disabling hip or knee arthritis and living in Ontario, Canada. Details of recruitment have been described previously. ${ }^{39-42}$ In brief, $100 \%$ of the population aged 55 or more in two areas of Ontario, Canada ( $n=48218$ ) were screened to identify those with hip or knee problems, irrespective of whether they were receiving care for these conditions. Participants reported the presence of symptomatic joints on a diagram (homunculus), the presence (or absence) of specific functional disabilities, and whether they had undergone previous arthroplasty. Respondents were selected for the baseline questionnaire if they had at least moderately severe hip or knee problems as defined by: difficulty in the past three months with each of stair climbing, rising from a chair, standing and walking; swelling, pain, or stiffness in any joint lasting more than six weeks in the past three months; and indication on the homunculus that a hip or knee, or both was "troublesome." For the current study we excluded participants with inflammatory arthritis $(n=186)$, those who moved out of the province $(n=4)$, and those we could not link to provincial databases ( $n=21$ ), resulting in a cohort of 2200 people (fig $1 \Downarrow$ ). The presence of hip or knee osteoarthritis in these people was confirmed both clinically and radiographically. ${ }^{39}$

Residents of Ontario have universal public health insurance under the Ontario Health Insurance Plan, the single payer for all medically necessary services. With participants' consent, we linked baseline questionnaire data with the following provincial health administrative databases to assess additional characteristics of the cohort, outcomes of interest, and receipt of total joint arthroplasty: physician services from Ontario Health Insurance Plan billing records, and admissions to hospital (inpatient and same day) from the Canadian Institute for Health Information discharge abstract database and National Ambulatory Care Reporting System database (which, from April 2002, records same day surgeries). To identify emergency department visits before 2002 we used the Ontario Health Insurance Plan and for visits from 2002 onwards we used the National Ambulatory Care Reporting System database. We identified inhospital deaths and causes of death from hospital discharge abstracts and deaths out of hospital from the Registered Persons Database. These datasets were held securely in a linked, deidentified form and analysed at the Institute for Clinical Evaluative Sciences. Wherever possible we used accepted, published, and validated outcome definitions, incorporating the transition from ICD-9 to ICD-10 coding (international classification of diseases, ninth and 10th revisions, respectively). ${ }^{43}$

\section{Study design}

As the date of receipt of total joint arthroplasty in this population was not related to the date of cohort entry, we utilised a landmark analysis ${ }^{44}$ to examine the effect of a primary, elective total joint arthroplasty on the occurrence of serious cardiovascular events. In a landmark analysis, a period of time between a baseline date (cohort entry) and a study start date (the landmark date) is designated the exposure period and chosen a priori. All exposures are classified during this time period; only outcomes that occur after the landmark date are counted in the analysis. Participants who experience the outcome of interest during the exposure window are excluded from subsequent analyses to avoid reverse causality and immortal time bias (which would tend to overestimate the benefit of the exposure). ${ }^{45}$ Exposures that occur after the landmark date do not affect group assignment.

For our study, cohort entry occurred at the time of completion of the baseline questionnaire. We chose a priori a landmark date of three years after completion of the questionnaire to ensure an adequate sample size of people who undergo total joint arthroplasty. Those who experienced a primary elective hip (ICD-9 codes 93.51 and 93.59) or knee replacement (ICD-9 code 93.41) during this period were considered exposed and those who did not were considered unexposed (regardless of whether they underwent a total joint arthroplasty after the landmark date). We excluded participants who had a cardiovascular event or died during the exposure period.

All included participants were then eligible for matching at the landmark date, and followed forward from the landmark date to the occurrence of the event of interest, or 1 April 2011, whichever came first.

\section{Covariates}

The baseline questionnaire assessed age, sex, height and weight (to calculate body mass index), annual household income, education, smoking status, self reported NSAID use (yes/no irrespective of dosage), living arrangements, severity of arthritis symptoms, health related quality of life (SF-36) ${ }^{47}$ and comorbidity (number of doctor diagnosed health problems for which they were receiving treatment or had seen a doctor in the past year). To assess the severity of symptoms we used the Western Ontario and McMaster Universities osteoarthritis index, using the total score (range $0-96$ ). ${ }^{39}$ We used two methods to identify the presence of pre-existing cardiovascular disease, hypertension, and diabetes: participant self report or based on validated algorithms ${ }^{48-50}$ utilising the Canadian Institute for Health Information discharge abstract and Ontario Health Insurance Plan databases (see supplementary appendix 1). We also used two methods to determine the presence of depression: participant self report or a score on the mental health subscale of the SF-36 consistent with depression $(<60 / 100) .{ }^{51}$

\section{Outcomes}

Our primary outcome was the occurrence of a serious cardiovascular event, which was defined as the occurrence of a visit to an emergency department or admission to hospital for acute myocardial infarction, stroke or transient ischaemic attack, congestive heart failure, coronary revascularisation (coronary artery bypass surgery or percutaneous coronary intervention), or inhospital deaths where the cause of death was a cardiovascular event (see supplementary appendix 1). 


\section{Statistical analysis}

We calculated baseline characteristics of the cohort using proportions and medians as appropriate, and we compared these before matching for exposed and unexposed participants using Wilcoxon rank sum tests for continuous variables and $\chi^{2}$ tests for categorical variables. Using a logistic regression model we determined a propensity score for undergoing a total joint arthroplasty within the exposure period. ${ }^{52}{ }^{33}$ The covariates entered into the propensity score were sociodemographic (age, sex, body mass index, living arrangements, education, annual household income), health status (number of comorbidities, SF-36 general health score, pre-existing cardiovascular disease, pre-existing depression, smoking status, use of NSAIDs), and severity of arthritis (Western Ontario and McMaster Universities arthritis index summary score, presence of troublesome hips and knees). We matched the exposed participants to unexposed participants on the logit of the propensity score using calipers of width equal to 0.2 of the standard deviation of the logit of the propensity score and on the presence or absence of pre-existing cardiovascular disease.$^{54} \mathrm{~A}$ matching ratio of $1: 1$ was used..$^{5}$

We estimated standardised differences for all covariates before and after matching, with a standardised difference of $10 \%$ or more considered indicative of imbalance. ${ }^{56}$ All subsequent analyses were performed in the matched sample, using methods appropriate for the analysis of matched data in estimating the treatment effect and its statistical significance. Kaplan-Meier survival curves were estimated in both groups, and we compared time to outcome using a stratified log-rank test. ${ }^{57}$ The hazard ratio for occurrence of a cardiovascular event was determined using Cox proportional hazards, after taking pair matching into account and using robust variance estimation. ${ }^{58}$ We estimated the absolute risk reduction and the number needed to treat for a seven year follow-up period.

We performed two subgroup analyses: an analysis stratified by the joint replaced (hip or knee), and an analysis limited to people with at least one of pre-existing cardiovascular disease, diabetes, or hypertension. We also performed sensitivity analyses, where we examined the effects of total joint arthroplasty using exposure windows of two years and four years. ${ }^{44}$ Finally, to ascertain the rate ratio and imbalance that a potential unmeasured confounder would have to have had to account for our findings we used an array approach. ${ }^{59}$ Analyses were performed using SAS version 9.3 for UNIX (SAS Institute, Cary, NC).

\section{Results}

\section{Cohort characteristics}

Of the 2200 cohort participants with validated osteoarthritis, $445(20.2 \%)$ experienced a serious cardiovascular event or died in the exposure period and were excluded from further analyses (table $1 \Downarrow$ ). Those excluded were on average older, more likely to live in a long term care facility, and more likely to have pre-existing cardiovascular disease but were similar for the prevalence of a pre-baseline total joint arthroplasty. Only 17 (3.8\%) excluded participants underwent a primary total joint arthroplasty during the exposure period. Of the 1755 remaining participants, $173(9.9 \%)$ had a primary total joint arthroplasty within the exposure period.

\section{Matching}

One hundred and fifty three participants $(88.4 \%, 91$ total knee arthroplasty, 62 total hip arthroplasty) who underwent a primary, elective total joint arthroplasty during the exposure period were successfully matched to a participant who did not (table $2 \Downarrow$ ). After matching, the absolute standardised differences were less than $10 \%$ for all variables entered into the propensity score, indicating an adequate match (table 2). Twenty participants who underwent a total joint arthroplasty could not be matched to a suitable control. Compared with those who were matched, the unmatched participants who had undergone a total joint arthroplasty were older (median age: non-matched 71 years, matched 70 years), had a higher mean body mass index (non-matched 31.4, matched 30.7), and had worse mean summary scores on the Western Ontario and McMaster Universities arthritis index (non-matched 52.3, matched 44.6). Fewer unmatched participants who had undergone a total joint arthroplasty had a cardiovascular event during the first seven years of follow-up (non-matched $25.0 \%$, matched $30.1 \%$ ).

\section{Outcomes after matching}

Overall, 111 (36.3\%) cardiovascular events occurred in the matched cohort (153 pairs) over a median follow-up period of seven years. Participants who underwent a total joint arthroplasty were less likely than those who did not to experience a cardiovascular event during follow-up (hazard ratio $0.56,95 \%$ confidence interval 0.43 to $0.74, \mathrm{P}<0.001$ ) (table $3 \Downarrow$ and fig $2 \Downarrow$ ). In a seven year follow-up period the absolute risk reduction was $12.4 \%$ (95\% confidence interval $1.7 \%$ to $23.1 \%$ ) and number needed to treat was 8 (95\% confidence interval 4 to 57 patients).

\section{Stratified analyses for total knee arthroplasty and total hip arthroplasty separately}

After excluding people who received a total hip arthroplasty, we were able to match 94 participants who underwent total knee arthroplasty to 94 people with moderate-severe knee osteoarthritis. Participants who underwent total knee arthroplasty were less likely than those who did not to experience a serious cardiovascular event during follow-up (hazard ratio 0.46, 95\% confidence interval 0.29 to $0.75, \mathrm{P}=0.0017$ ). However, the groups were not adequately balanced, with the total knee arthroplasty group having a higher proportion of men $(26.6 \%$ $v 19.1 \%$, standardised difference $18 \%$ ).

After excluding people who had undergone a total knee arthroplasty, we were able to successfully match 49 participants who had undergone a total hip arthroplasty to 49 people with moderate-severe hip osteoarthritis. Participants who had undergone a total hip arthroplasty were less likely than those who did not to experience serious cardiovascular events (hazard ratio $0.61,95 \%$ confidence interval 0.38 to $0.99, \mathrm{P}=0.0442$ ). However, the groups were not adequately balanced, with those who had undergone a total hip arthroplasty having a higher median age ( $70 v 68$ years, standardised difference 16\%) and a higher mean body mass index $(32.8 v 29.2$, standardised difference $32 \%$ ).

\section{Subgroup analysis-people with at least one risk factor for cardiovascular disease}

There were 1153 participants with at least one risk factor for cardiovascular disease who were event free at the end of the three year exposure period and therefore eligible for matching. Of these, $144(12.5 \%)$ underwent a primary total joint arthroplasty during the exposure period, of whom 121 (84\%) were successfully matched to a participant who did not. After matching, undergoing total joint arthroplasty was associated with a significant decrease in the risk for a cardiovascular event (hazard ratio 0.71, $\mathrm{P}=0.0273$ ). However, the groups were not 
satisfactorily balanced, with the total joint arthroplasty group having a higher prevalence of participants living in an urban area (no total joint arthroplasty $27.3 \%$, total joint arthroplasty $34.7 \%$, standardised difference $16 \%$ ).

\section{Sensitivity analyses}

Similar results to our main analysis were obtained when we used exposure windows of different lengths. When a two year window was used, total joint arthroplasty was associated with a significant decrease in the risk for cardiovascular events (hazard ratio $0.67, \mathrm{P}=0.0078$ ), but the groups were not well balanced, with the median age of the total joint arthroplasty group being slightly lower than that of the group that had not undergone total joint arthroplasty (70 $v 71$ years, standardised difference 18\%). Using an exposure window of four years, the groups were balanced (standardised difference under $10 \%$ for all assessed covariates) and the results similar (hazard ratio 0.57 , $\mathrm{P}<0.001$ ).

A theoretical unmeasured confounder, if not collinear with other covariates, would have to have had a prevalence of at least $75 \%$ in one group, and be completely absent from the other group, with a relative risk ratio of at least 0.65 (if found only among those who underwent total joint arthroplasty) or 1.50 (if found only among those who had not undergone total joint arthroplasty) to account for the observed effect with total joint arthroplasty.

\section{Discussion}

This population based study of people with moderate-severe osteoarthritis shows that undergoing an elective primary total joint arthroplasty within three years of initial assessment was associated with a significant $40 \%$ reduction in subsequent risk of serious cardiovascular events in patients who survived until the landmark date (three years from the baseline questionnaire). This translated into an absolute risk reduction of $12.4 \%$ and a number needed to treat of 8 over a seven year follow-up period. Although our study was observational, we were able to show this effect after accounting for a large number of cardiovascular risk factors and potential confounders using propensity matching. To our knowledge, this is the first study to demonstrate a possible cardioprotective benefit of total joint arthroplasty.

There are several potential explanations for our findings. Total joint arthroplasty may improve capability for physical activity. It has been shown to improve walking distance and physical capability in people with moderate to severe osteoarthritis. ${ }^{60-70}$ Moderate intensity physical activity (for example, a brisk walk) a few days a week has direct benefits for hypertension, ${ }^{71-73}$ obesity ${ }^{74.76}$ and diabetes,${ }^{778}$ which are highly prevalent in people with osteoarthritis, ${ }^{79-81}$ and in people with established risk factors for cardiovascular disease. ${ }^{4-68913}$ In our study population, $66 \%$ of the participants who were eligible for matching had one or more of these risk factors. Total joint arthroplasty may also reduce the risk for serious cardiovascular events by relieving pain, and thus psychosocial stress, which is also an established risk factor for a cardiovascular event. ${ }^{14-18}{ }^{31-36}$ While we did not directly measure participants' levels of stress, $34.0 \%$ (747/2200) of our participants who had undergone total joint arthroplasty had probable depression at the baseline assessment. Total joint arthroplasty is highly effective in reducing pain and improving mood in people with moderate-severe osteoarthritis. ${ }^{60}{ }^{62}$ Finally, improvement in pain after total joint arthroplasty may be associated with reduced use of non-steroidal anti-inflammatory drugs (NSAIDs), which in turn are associated with an increased risk for cardiovascular events. ${ }^{82-85}$ At baseline, $37.4 \%$ (822/2200) of the participants who had undergone total joint arthroplasty self reported use of NSAIDs. We have previously shown that use of prescription drugs for pain management decreased after total joint arthroplasty ${ }^{42}$; whether NSAID use in particular declines is unclear owing to the widespread availability of over the counter NSAIDs. Further research is warranted to examine the role of physical activity, pain relief, improvement in mood and stress, and reduction in use of NSAIDs on the observed relation between total joint arthroplasty and subsequent serious cardiovascular events.

We studied a well defined population cohort of people with moderate-severe osteoarthritis to determine if total joint arthroplasty impacted the rates of subsequent cardiovascular events. As the date of undergoing total joint arthroplasty in this population was not related to the date of cohort entry, we utilised a landmark analysis. Owing to the relatively small sample of participants who underwent total joint arthroplasty in the cohort, we determined a priori that we would require an exposure window of three years for an adequate sample size. As a result, we excluded 445 participants who had a cardiovascular event or died during the exposure window from subsequent analysis. Excluded participants were older, sicker, and more likely to have had a prebaseline cardiovascular event. Therefore, it might be argued that these people would be less likely to be offered total joint arthroplasty; if so, their inclusion in our analyses would have biased our results in favour of total joint arthroplasty. We also performed sensitivity analyses with exposure windows of varying length,${ }^{44}$ and the cardioprotective effect of total joint arthroplasty remained consistent. This suggests that our findings are not the result of our chosen exposure window.

The cardioprotective benefit of total joint arthroplasty was still observed after stratifying by the joint being replaced (hip or knee). The groups were not adequately balanced, with the total knee arthroplasty group having a higher proportion of men than the non-total knee arthroplasty group, and the total hip arthroplasty group having a higher median age than the non-total hip arthroplasty group. However, as older age and male sex are risk factors for cardiovascular disease ${ }^{86}$ the unbalanced nature of these matched groups would tend to bias against total knee arthroplasty and total hip arthroplasty, respectively. Knee osteoarthritis is strongly associated with metabolic syndrome, ${ }^{87-89}$ and this analysis suggested that total knee arthroplasty had a greater cardioprotective benefit than total hip arthroplasty. Further studies, with larger sample sizes, are required to confirm if any cardioprotective benefit of total joint arthroplasty varies by the joint being replaced.

The main analysis suggested that the cardioprotective benefit of total joint arthroplasty was most pronounced in the first four years of follow-up, after which the survival curves were essentially parallel. This is partly due to our use of baseline factors to predict long term outcome - the effects of any exposure will lessen over time. Should the benefits be confirmed in larger studies, this would support consideration of total joint arthroplasty not only as an elective procedure to improve quality of life. Instead, the careful weighing of health benefits, including a reduction in cardiovascular disease risk, with both short and longer term risks may be warranted.

\section{Strengths and limitations of this study}

Strengths of our study include its use of a well defined population cohort that yielded rich patient level information not readily available in administrative databases (for example, 
arthritis severity), and allowed us to compare those who had undergone a total joint arthroplasty with others who had moderate-severe arthritis of the hip or knee. Our use of a propensity score helped mitigate bias due to confounding by indication, as well as to balance a wide range of cardiovascular risk factors between groups, including pre-existing cardiovascular disease, ${ }^{4}$ diabetes,${ }^{6-8}$ hypertension,,${ }^{45}$ smoking status, ${ }^{10}$ body mass index, ${ }^{12} 13$ and living arrangements. ${ }^{90}$ Finally, linkage with administrative databases allowed for the follow-up of each patient regardless of further participation, allowing us to avoid attrition over time.

However, there are also limitations in addition to those already discussed. Foremost, use of a landmark analysis with a three year exposure window means that our findings around the cardioprotective benefit of total joint arthroplasty only apply to patients who are event free at three years after initial cohort assessment. Our study participants were aged 55 or more and had osteoarthritis. While this reflects most people who undergo a total joint arthroplasty, our findings may not be generalisable to younger people or those with inflammatory arthritis. Although we controlled for several confounders, we were unable to account for factors such as motivation for lifestyle modification, ${ }^{91}$ which increases someone's likelihood of undergoing a total joint arthroplasty and their level of physical activity. We also did not have any information on levels of physical activity, use of cardioprotective drugs at any point during the study, use of NSAIDs after surgery, the presence of hyperlipidaemia, or the presence of renal insufficiency. However, as we have shown, any unmeasured confounder would have to be unrelated to the variables balanced by the propensity score and would need to have a large prevalence and be strongly associated with the outcome to explain our results.

\section{Conclusions}

A propensity score matched landmark analysis of a population cohort with moderate-severe hip or knee osteoarthritis, undergoing total joint arthroplasty within three years of baseline assessment reduced the subsequent risk of cardiovascular disease. While these findings require confirmation in larger studies, they provide further justification for increased attention to the impact of treatments directed towards osteoarthritis related disability in the prevention and management of other common chronic conditions such as cardiovascular disease.

Contributors: BR is the guarantor. The opinions, results and conclusions reported in this paper are those of the authors and are independent from the funding sources. No endorsement by the Institute for Clinical Evaluative Sciences or the Ontario Ministry of Health and Long-Term Care is intended or should be inferred. All authors were involved in study conception and gave final approval for the submission. GAH created the clinical cohort that served as the information source for the study. BR, RC, PCA, and GAH were involved with the study design and statistical analysis. BR and GAH wrote the initial draft and were responsible for subsequent modifications based on feedback from the other authors and from the reviewers.

Funding: This study was supported by the Institute for Clinical Evaluative Sciences, which is funded by an annual grant from the Ontario Ministry of Health and Long-Term Care. The opinions, results and conclusions reported in this paper are those of the authors and are independent from the funding sources. No endorsement by the Institute for Clinical Evaluative Sciences or the Ontario Ministry of Health and Long-Term Care is intended or should be inferred. BR is supported in part by a doctoral award from the Canadian Institutes of Health Research. PCA is supported in part by a career investigator award from the Heart and Stroke Foundation. GAH is supported in part by the FM Hill chair in academic women's medicine, and Canadian Institutes of Health Research grant No MOP-15468. ICES received support from the Ministry of Health and Long-Term Care.

Competing interests: All authors have completed the ICMJE uniform disclosure form at www.icmje.org/coi_disclosure.pdf and declare: no support from any organisation for the submitted work; no financial relationships with any organisations that might have an interest in the submitted work in the previous three years; no other relationships or activities that could appear to have influenced the submitted work.

Ethical approval: This study was approved by the Sunnybrook Health Sciences Centre, Toronto, Ontario, Canada.

Data sharing: No additional data available.

Transparency: BR affirms that the manuscript is an honest, accurate, and transparent account of the study being reported; that no important aspects of the study have been omitted; and that any discrepancies from the study as planned (and, if relevant, registered) have been explained.

1 Global atlas on cardiovascular disease prevention and control. Policies, strategies and interventions. World Health Organization, World Heart Federation, and World Stroke Organization, 2011

2 Yusuf S, Reddy S, Ounpuu S, Anand S. Global burden of cardiovascular diseases: part II: variations in cardiovascular disease by specific ethnic groups and geographic regions and prevention strategies. Circulation 2001;104:2855-64.

3 Yusuf S, Reddy S, Ounpuu S, Anand S. Global burden of cardiovascular diseases: part I: general considerations, the epidemiologic transition, risk factors, and impact of urbanization. Circulation 2001;104:2746-53.

4 World Health Organization. The global burden of disease: 2004 update. WHO, 2008.

5 Cook NR, Cutler JA, Obarzanek E, Buring JE, Rexrode KM, Kumanyika SK, et al. Long term effects of dietary sodium reduction on cardiovascular disease outcomes: observational follow-up of the trials of hypertension prevention (TOHP). BMJ 2007;334:885-8.

6 Chun BY, Dobson AJ, Heller RF. The impact of diabetes on survival among patients with first myocardial infarction. Diabetes Care 1997;20:704-8.

7 Ho JE, Paultre F, Mosca L, Women's Pooling Project. Is diabetes mellitus a cardiovascular disease risk equivalent for fatal stroke in women? Data from the Women's Pooling Project. Stroke 2003;34:2812-6.

8 McCarron P, Greenwood R, Elwood P, Shlomo YB, Bayer A, Baker I, et al. The incidence and aetiology of stroke in the Caerphilly and Speedwell Collaborative Studies II: risk factors for ischaemic stroke. Public Health 2001;115:12-20

9 Stamler J, Vaccaro O, Neaton JD, Wentworth D. Diabetes, other risk factors, and 12-yr cardiovascular mortality for men screened in the Multiple Risk Factor Intervention Trial. Diabetes Care 1993:16:434-44.

10 Ambrose JA, Barua RS. The pathophysiology of cigarette smoking and cardiovascular disease: an update. J Am Coll Cardiol 2004;43:1731-7.

11 Ockene IS, Miller NH. Cigarette smoking, cardiovascular disease, and stroke: a statement for healthcare professionals from the American Heart Association. American Heart Association Task Force on Risk Reduction. Circulation 1997;96:3243-7.

12 Hubert HB, Feinleib M, McNamara PM, Castelli WP. Obesity as an independent risk factor for cardiovascular disease: a 26 -year follow-up of participants in the Framingham Heart Study. Circulation 1983;67:968-77.

13 Must A, Spadano J, Coakley EH, Field AE, Colditz G, Dietz WH. The disease burden associated with overweight and obesity. JAMA 1999;282:1523-9.

14 Kawachi I, Sparrow D, Vokonas PS, Weiss ST. Symptoms of anxiety and risk of coronary heart disease. The Normative Aging Study. Circulation 1994;90:2225-9.

15 Bunker SJ, Colquhoun DM, Esler MD, Hickie IB, Hunt D, Jelinek VM, et al. "Stress" and coronary heart disease: psychosocial risk factors. Med J Austr 2003;178:272-6.

16 Blumenthal JA, Sherwood A, Babyak MA, Watkins LL, Waugh R, Georgiades A, et al. Effects of exercise and stress management training on markers of cardiovascular risk in patients with ischemic heart disease: a randomized controlled trial. JAMA 2005:293:1626-34.

17 Bavry AA, Khaliq A, Gong Y, Handberg EM, Cooper-Dehoff RM, Pepine CJ. Harmful effects of NSAIDs among patients with hypertension and coronary artery disease. Am J Med 2011;124:614-20.

18 Graham DJ. COX-2 inhibitors, other NSAIDs, and cardiovascular risk: the seduction of common sense. JAMA 2006;296:1653-6.

19 Yudkin JS, Kumari M, Humphries SE, Mohamed-Ali V. Inflammation, obesity, stress and coronary heart disease: is interleukin-6 the link? Atherosclerosis 2000;148:209-14.

20 Kritharides L. Inflammatory markers and outcomes in cardiovascular disease. PLOS Med 2009;6:e1000147.

21 Pearson TA, Blair SN, Daniels SR, Eckel RH, Fair JM, Fortmann SP, et al. AHA guidelines for primary prevention of cardiovascular disease and stroke: 2002 update: consensus panel guide to comprehensive risk reduction for adult patients without coronary or other atherosclerotic vascular diseases. American Heart Association Science Advisory and Coordinating Committee. Circulation 200216;106:388-91.

22 Leon AS, Franklin BA, Costa F, Balady GJ, Berra KA, Stewart KJ, et al. Cardiac rehabilitation and secondary prevention of coronary heart disease: an American Heart Association scientific statement from the Council on Clinical Cardiology (Subcommittee on Exercise, Cardiac Rehabilitation, and Prevention) and the Council on Nutrition, Physical Activity, and Metabolism (Subcommittee on Physical Activity), in collaboration with the American association of Cardiovascular and Pulmonary Rehabilitation. [Erratum appears in Circulation 2005;111:1717]. Circulation 2005;111:369-76.

23 Lee IM, Shiroma EJ, Lobelo F, Puska P, Blair SN, Katzmarzyk PT, et al. Effect of physical inactivity on major non-communicable diseases worldwide: an analysis of burden of disease and life expectancy. Lancet 2012;380:219-29.

24 Agency for Healthcare Research and Quality. Physical activity and older Americans: benefits and strategies. www.ahrqgov/ppip/activityhtm. June 2002. 


\section{What is already known on this topic}

Osteoarthritis is associated with increased mortality, particularly secondary to cardiovascular disease

The risk for mortality is proportional to the degree of disability secondary to osteoarthritis

Increased use of non-steroidal anti-inflammatory drugs and psychosocial stress in people with osteoarthritis may exacerbate this risk

\section{What this study adds}

In people with moderate-severe osteoarthritis, elective primary total joint arthroplasty within three years of initial assessment was associated with a significant $40 \%$ reduction in subsequent risk of serious cardiovascular events

While our study was observational, we were able to show this effect after accounting for a large number of cardiovascular risk factors and potential confounders using propensity matching

25 Roger VL GA, Lloyd-Jones DM, Benjamin EJ, Berry JD, Borden WB, Bravata DM, et al; on behalf of the American Heart Association Statistics Committee and Stroke Statistics Subcommittee. Heart disease and stroke statistics-2012 update: a report from the American Heart Association. Circulation 2012; 125:e2-220.

26 Adamson J, Lawlor DA, Ebrahim S. Chronic diseases, locomotor activity limitation and social participation in older women: cross sectional survey of British Women's Heart and Health Study. Age Ageing 2004;33:293-8.

27 Peat G, McCarney R, Croft P. Knee pain and osteoarthritis in older adults: a review of community burden and current use of primary health care. Ann Rheum Dis 2001;60:91-7.

28 Hawker GA Badley EM, Jaglal S, Dunn S, Croxford R, Ko B, et al. Musculoskeletal conditions. In: Bierman AS, ed. Project for an Ontario Women's Health Evidence-Based Report: vol 2: Toronto. 2010.

29 Nuesch E, Dieppe P, Reichenbach S, Williams S, Iff S, Juni P. All cause and disease specific mortality in patients with knee or hip osteoarthritis: population based cohort study BMJ 2011;342:d1165.

30 Hochberg MC, Altman RD, Brandt KD, Clark BM, Dieppe PA, Griffin MR, et al. Guidelines for the medical management of osteoarthritis. Part II. Osteoarthritis of the knee. American College of Rheumatology. Arthritis Rheum 1995;38:1541-6.

31 Davis MC, Zautra AJ, Reich JW. Vulnerability to stress among women in chronic pain from fibromyalgia and osteoarthritis. Ann Behav Med 2001;23:215-26.

32 Weinberger M, Tierney WM, Booher P, Hiner SL. Social support, stress and functional status in patients with osteoarthritis. Soc Sci Med 1990;30:503-8

33 Creamer P, Lethbridge-Cejku M, Costa P, Tobin JD, Herbst JH, Hochberg MC. The relationship of anxiety and depression with self-reported knee pain in the community: data from the Baltimore Longitudinal Study of Aging. Arthritis Care Res 1999;12:3-7.

34 Zautra AJ, Smith BW. Depression and reactivity to stress in older women with rheumatoid arthritis and osteoarthritis. Psychosom Med 2001;63:687-96.

35 Memel DS, Kirwan JR, Sharp DJ, Hehir M. General practitioners miss disability and anxiety as well as depression in their patients with osteoarthritis. Br J Gen Pract 2000;50:645-8.

36 Scopaz KA, Piva SR, Wisniewski S, Fitzgerald GK. Relationships of fear, anxiety, and depression with physical function in patients with knee osteoarthritis. Arch Phys Med Rehabil 2009;90:1866-73.

37 Lamb SE, Frost $\mathrm{H}$. Recovery of mobility after knee arthroplasty: expected rates and influencing factors. J Arthroplasty 2003;18:575-82.

38 Sicard-Rosenbaum L, Light KE, Behrman AL. Gait, lower extremity strength, and self-assessed mobility after hip arthroplasty. J Gerontol A Biol Sci Med Sci 2002;57:M47-51

39 Hawker GA, Wright JG, Coyte PC, Williams JI, Harvey B, Glazier R, et al. Differences between men and women in the rate of use of hip and knee arthroplasty. N Engl J Med 2000;342:1016-22.

40 Hawker GA, Guan J, Croxford R, Coyte PC, Glazier RH, Harvey BJ, et al. A prospective population-based study of the predictors of undergoing total joint arthroplasty. Arthritis Rheum 2006;54:3212-20.

41 Hawker GA, Wright JG, Badley EM, Coyte PC. Perceptions of, and willingness to consider, total joint arthroplasty in a population-based cohort of individuals with disabling hip and knee arthritis. Arthritis Rheum 2004;51:635-41.

42 Hawker GA, Wright JG, Coyte PC, Williams JI, Harvey B, Glazier R, et al. Determining the need for hip and knee arthroplasty: the role of clinical severity and patients' preferences. Med Care 2001;39:206-16.

43 Canadian Institute for Health Information. The international statistical classification of diseases and related health problems, 10 th revision. Canadian Institute for Health Information, 2003.

44 Dafni U. Landmark analysis at the 25-year landmark point. Circ Cardiovasc Qual Outcomes 2011;4:363-71.

45 Beyersmann J, Gastmeier P, Wolkewitz M, Schumacher M. An easy mathematical proof showed that time-dependent bias inevitably leads to biased effect estimation. J Clin Epidemiol 2008;61:1216-21.

46 Anderson JR, Cain KC, Gelber RD. Analysis of survival by tumor response and other comparisons of time-to-event by outcome variables. J Clin Oncol 2008;26:3913-5.

47 Ware JE Jr, Sherbourne CD. The MOS 36-item short-form health survey (SF-36). I. Conceptual framework and item selection. Med Care 1992;30:473-83.

48 Ko DT, Mamdani M, Alter DA. Lipid-lowering therapy with statins in high-risk elderly patients: the treatment-risk paradox. JAMA 2004;291:1864-70.

49 Lipscombe LL, Hux JE. Trends in diabetes prevalence, incidence, and mortality in Ontario, Canada 1995-2005: a population-based study. Lancet 2007;369:750-6.

50 Tu K, Chen Z, Lipscombe LL, Canadian Hypertension Education Program Outcomes Research T. Prevalence and incidence of hypertension from 1995 to 2005: a population-based study. CMAJ 2008;178:1429-35.

51 Friedman B, Heisel M, Delavan R. Validity of the SF-36 five-item Mental Health Index for major depression in functionally impaired, community-dwelling elderly patients. J Am Geriatr Soc 2005;53:1978-85.

52 Austin P. An introduction to propensity score methods for reducing the effects of confounding in observational studies. Multivariate Behav Res 2011;46:399-424.

53 Austin P. A Tutorial and case study in propensity score analysis: an application to estimating the effect of in-hospital smoking cessation counseling on mortality. Multivariate Behav Res 2011;46:119-51.
54 Austin PC. Optimal caliper widths for propensity-score matching when estimating differences in means and differences in proportions in observational studies. Pharm Stat 2011;10:150-61.

55 Austin PC. Comparing paired vs non-paired statistical methods of analyses when making inferences about absolute risk reductions in propensity-score matched samples. Stat Med 2011;30:1292-301.

56 Austin PC. Balance diagnostics for comparing the distribution of baseline covariates between treatment groups in propensity-score matched samples. Stat Med 2009;28:3083-107

57 Austin PC. Type I error rates, coverage of confidence intervals, and variance estimation in propensity-score matched analyses. Int J Biostat 2009;5:Article 13.

58 Barlow WE. Robust variance estimation for the case-cohort design. Biometrics 1994;50:1064-72.

59 Schneeweiss S. Sensitivity analysis and external adjustment for unmeasured confounders in epidemiologic database studies of therapeutics. Pharmacoepidemiol Drug Saf 2006;15:291-303.

60 Ethgen O, Bruyere O, Richy F, Dardennes C, Reginster J-Y. Health-related quality of life in total hip and total knee arthroplasty. A qualitative and systematic review of the literature. $J$ Bone Joint Surg 2004:86-A:963-74.

61 Jandric S, Manojlovic S. Quality of life of men and women with osteoarthritis of the hip and arthroplasty: assessment by WOMAC questionnaire. Am J Phys Med Rehabil 2009;88:328-35

62 Jones CA, Beaupre LA, Johnston DWC, Suarez-Almazor ME. Total joint arthroplasties: current concepts of patient outcomes after surgery. Rheum Dis Clin North Am 2007;33:71-86.

63 Jones CA, Voaklander DC, Johnston DW, Suarez-Almazor ME. Health related quality of life outcomes after total hip and knee arthroplasties in a community based population. $J$ Rheumatol 2000;27:1745-52

64 Mariconda M, Galasso O, Costa GG, Recano P, Cerbasi S. Quality of life and functionality after total hip arthroplasty: a long-term follow-up study. BMC Musculoskelet Disord 2011;12:222.

65 Montin L, Leino-Kilpi H, Suominen T, Lepisto J. A systematic review of empirical studies between 1966 and 2005 of patient outcomes of total hip arthroplasty and related factors. $J$ Clin Nurs 2008;17:40-5.

66 Quintana JM, Escobar A, Arostegui I, Bilbao A, Azkarate J, Goenaga JI, et al. Health-related quality of life and appropriateness of knee or hip joint replacement. Arch Intern Med 2006;166:220-6.

67 Bauman S, Williams D, Petruccelli D, Elliott W, de Beer J. Physical activity after total joint replacement: a cross-sectional survey. Clin J Sport Med 2007;17:104-8.

68 Mahon JL, Bourne RB, Rorabeck CH, Feeny DH, Stitt L, Webster-Bogaert S. Health-related quality of life and mobility of patients awaiting elective total hip arthroplasty: a prospective study. CMAJ 2002;167:1115-21.

69 Stevens M, Reininga IHF, Bulstra SK, Wagenmakers R, van den Akker-Scheek I. Physical activity participation among patients after total hip and knee arthroplasty. Clin Geriatr Med 2012:28:509-20.

70 Woolf VJ, Charnley GJ, Goddard NJ. Weight changes after total hip arthroplasty. J Arthroplasty 1994;9:389-91.

71 Haapanen N, Millunpalo S, Vuori I, Oja P, Pasanen M. Association of leisure time physical activity with the risk of coronary heart disease, hypertension and diabetes in middle-aged men and women. Int J Epidemiol 1997:26:739-47.

72 Nelson L, Jennings GL, Esler MD, Korner PI. Effect of changing levels of physical activity on blood-pressure and haemodynamics in essential hypertension. Lancet 1986;2:473-6.

73 Pereira MA, Folsom AR, McGovern PG, Carpenter M, Arnett DK, Liao D, et al. Physical activity and incident hypertension in black and white adults: the Atherosclerosis Risk in Communities Study. Prevent Med 1999;28:304-12.

74 Poirier P, Giles TD, Bray GA, Hong Y, Stern JS, Pi-Sunyer FX, et al. Obesity and cardiovascular disease: pathophysiology, evaluation, and effect of weight loss. Arterioscler Thromb Vasc Biol 2006;26:968-76.

75 Ryan DH, Espeland MA, Foster GD, Haffner SM, Hubbard VS, Johnson KC, et al. Look AHEAD (Action for Health in Diabetes): design and methods for a clinical trial of weight loss for the prevention of cardiovascular disease in type 2 diabetes. Control Clin Trials 2003;24:610-28.

76 Thompson PD, Buchner D, Pina IL, Balady GJ, Williams MA, Marcus BH, et al. Exercise and physical activity in the prevention and treatment of atherosclerotic cardiovascular disease: a statement from the Council on Clinical Cardiology (Subcommittee on Exercise, Rehabilitation, and Prevention) and the Council on Nutrition, Physical Activity, and Metabolism (Subcommittee on Physical Activity). Circulation 2003;107:3109-16.

77 Helmrich SP, Ragland DR, Leung RW, Paffenbarger RS Jr. Physical activity and reduced occurrence of non-insulin-dependent diabetes mellitus. N Engl J Med 1991;325:147-52.

78 Lindstrom J, Louheranta A, Mannelin M, Rastas M, Salminen V, Eriksson J, et al. The Finnish Diabetes Prevention Study (DPS): lifestyle intervention and 3-year results on diet and physical activity. Diabetes Care 2003;26:3230-6.

79 Prior JA RC, Jordan KP, Kadam UT. Comorbidity Cohort (2C) study: cardiovascular disease severity and comorbid osteoarthritis in primary care. BMC Health Serv Res 2012;12:295. 
80 Singh G, Miller JD, Lee FH, Pettitt D, Russell MW. Prevalence of cardiovascular disease risk factors among US adults with self-reported osteoarthritis: data from the Third National Health and Nutrition Examination Survey. Am J Manag Care 2002;8(15 Suppl):S383-91.

81 Vogeli C, Shields AE, Lee TA, Gibson TB, Marder WD, Weiss KB, et al. Multiple chronic conditions: prevalence, health consequences, and implications for quality, care management, and costs. J Gen Intern Med 2007;22(Suppl 3):391-5.

82 Graham DJ, Campen D, Hui R, Spence M, Cheetham C, Levy G, et al. Risk of acute myocardial infarction and sudden cardiac death in patients treated with cyclo-oxygenase 2 selective and non-selective non-steroidal anti-inflammatory drugs: nested case-control study. Lancet 2005;365:475-81.

83 Johnsen SP, Larsson H, Tarone RE, McLaughlin JK, Norgard B, Friis S, et al. Risk of hospitalization for myocardial infarction among users of rofecoxib, celecoxib, and other NSAIDs: a population-based case-control study. Arch Intern Med 2005;165:978-84.

84 Mukherjee D, Nissen SE, Topol EJ. Risk of cardiovascular events associated with selective COX-2 inhibitors. JAMA 2001;286:954-9.

85 White WB. Cardiovascular risk, hypertension, and NSAIDs. Curr Pain Headache Rep 2007;11:428-35.

86 Jousilahti P, Vartiainen E, Tuomilehto J, Puska P. Sex, age, cardiovascular risk factors, and coronary heart disease: a prospective follow-up study of 14786 middle-aged men and women in Finland. Circulation 1999:99:1165-72.

87 Engstrom G, Gerhardsson de Verdier M, Rollof J, Nilsson PM, Lohmander LS. C-reactive protein, metabolic syndrome and incidence of severe hip and knee osteoarthritis. A population-based cohort study. Osteoarthritis Cartilage 2009;17:168-73.
88 Han C, Yang I, Lee W, Park Y, Park K. Correlation between metabolic syndrome and knee osteoarthritis: data from the Korean National Health and Nutrition Examination Survey (KNHANES). BMC Public Health 2013;13:603.

89 Inoue R, Ishibashi Y, Tsuda E, Yamamoto Y, Matsuzaka M, Takahashi I, et al. Medical problems and risk factors of metabolic syndrome among radiographic knee osteoarthritis patients in the Japanese general population. J Orthop Sci 2011;16:704-9.

90 Udell JA, Steg PG, Scirica BM, Smith SC Jr, Ohman EM, Eagle KA, et al. Living alone and cardiovascular risk in outpatients at risk of or with atherothrombosis. Arch Intern Med 2012;172:1086-95.

91 Quintana JM, Arostegui I, Escobar A, Azkarate J, Goenaga JI, Lafuente I. Prevalence of knee and hip osteoarthritis and the appropriateness of joint replacement in an older population. Arch Intern Med 2008;168:1576-84.

\section{Accepted: 23 September 2013}

\section{Cite this as: BMJ 2013;347:f6187}

This is an Open Access article distributed in accordance with the Creative Commons Attribution Non Commercial (CC BY-NC 3.0) license, which permits others to distribute, remix, adapt, build upon this work non-commercially, and license their derivative works on different terms, provided the original work is properly cited and the use is non-commercial. See: http://creativecommons.org/licenses/by-nc/3.0/. 


\section{Tables}

Table 1/ Characteristics of cohort at baseline assessment. Values are numbers (percentages) unless stated otherwise

\begin{tabular}{|c|c|c|c|c|}
\hline Characteristics & Entire cohort $(n=2200)$ & Excluded participants ( $n=445$ ) & Included participants ( $n=1755$ ) & P value ${ }^{*}$ \\
\hline Median (interquartile range) age (years) & $71(64-78)$ & $77(71-83)$ & $70(63-76)$ & $<0.001$ \\
\hline Women & $1585(72.0)$ & $286(64.3)$ & $1299(74.0)$ & $<0.001$ \\
\hline Median (interquartile range) hip pain & $1363(62.8)$ & $1074(61.2)$ & $289(64.9)$ & 0.146 \\
\hline Median (interquartile range) knee pain & $1913(87.0)$ & $1531(87.2)$ & $382(85.8)$ & 0.436 \\
\hline $\begin{array}{l}\text { Median (interquartile range) body mass } \\
\text { index }\end{array}$ & $28(24-31)$ & $27(23-30)$ & $28(25-32)$ & $<0.001$ \\
\hline Urban dwelling & 965 (43.9) & $211(47.4)$ & $754(43.0)$ & 0.091 \\
\hline \multicolumn{5}{|l|}{ Living conditions: } \\
\hline Lives alone & $720(32.7)$ & $160(36.0)$ & $560(31.9)$ & \multirow[t]{3}{*}{$<0.001$} \\
\hline Lives with others & $1439(58.7)$ & $261(58.7)$ & $1178(67.1)$ & \\
\hline Lives in long term care facility & $41(1.9)$ & $24(5.4)$ & $17(1.0)$ & \\
\hline \multicolumn{5}{|l|}{ Income (\$C): } \\
\hline$>20000$ & $654(29.7)$ & $126(28.3)$ & $528(30.1)$ & \multirow[t]{3}{*}{0.477} \\
\hline$\leq 20000$ & $1150(52.3)$ & $244(54.8)$ & $906(51.6)$ & \\
\hline Missing & $396(18.0)$ & $75(16.9)$ & $321(18.3)$ & \\
\hline \multicolumn{5}{|l|}{ Smoker: } \\
\hline Never & $1030(48.2)$ & $195(45.7)$ & $835(48.9)$ & \multirow[t]{3}{*}{0.406} \\
\hline Former & $792(37.1)$ & $170(39.8)$ & $622(36.4)$ & \\
\hline Current & $313(14.7)$ & $62(14.5)$ & $251(14.7)$ & \\
\hline NSAID use & $822(37.4)$ & $157(35.3)$ & $665(37.9)$ & 0.309 \\
\hline \multicolumn{5}{|l|}{ No of comorbidities: } \\
\hline 0 & $95(4.3)$ & $15(3.4)$ & $80(4.6)$ & \multirow[t]{5}{*}{$<0.001$} \\
\hline 1 & $398(18.1)$ & $62(13.9)$ & $336(19.1)$ & \\
\hline 2 & $686(31.2)$ & $131(29.4)$ & $555(31.6)$ & \\
\hline 3 & $584(26.5)$ & $120(27.0)$ & $464(26.4)$ & \\
\hline$\geq 4$ & $437(19.9)$ & $117(26.3)$ & $320(18.2)$ & \\
\hline Pre-existing cardiovascular disease & $274(12.5)$ & $129(29.0)$ & $145(8.3)$ & $<0.001$ \\
\hline Diabetes & $400(18.2)$ & $127(28.5)$ & $273(15.6)$ & $<0.001$ \\
\hline Depression & $747(34.0)$ & $168(37.8)$ & $579(33.0)$ & 0.058 \\
\hline Hypertension & $1394(63.4)$ & $321(72.1)$ & $1073(61.1)$ & $<0.001$ \\
\hline Median (interquartile range) SF-36 & $47(30-67)$ & $50(35-67)$ & $40(25-57)$ & $<0.001$ \\
\hline $\begin{array}{l}\text { Median (interquartile range) WOMAC } \\
\text { score }\end{array}$ & $42(27-54)$ & $46(31-56)$ & $41(26-53)$ & $<0.001$ \\
\hline Pre-baseline total joint arthroplasty & $235(10.7)$ & $44(9.9)$ & $191(10.9)$ & 0.544 \\
\hline
\end{tabular}

Pre-baseline total joint arthroplasty

$235(10.7)$

$191(10.9)$

NSAID=non-steroidal anti-inflammatory drug; SF-36=short-form-36 general health survey; WOMAC=Western Ontario and McMaster Universities arthritis index. ${ }^{*}$ Comparison of included and excluded groups; excluded participants had a cardiovascular event or died within the exposure period (three years after baseline questionnaire). 
Table 2/ Comparison of patients with and without a primary total joint arthroplasty within three years of baseline questionnaire before and after matching. Values are numbers (percentages) unless stated otherwise

\begin{tabular}{|c|c|c|c|c|c|c|}
\hline \multirow[b]{2}{*}{ Characteristics } & \multicolumn{3}{|c|}{ Exposure groups before matching } & \multicolumn{3}{|c|}{ Exposure groups after matching } \\
\hline & $\begin{array}{l}\text { No arthroplasty } \\
\quad(n=1582)\end{array}$ & Arthoplasty $(n=173)$ & $\begin{array}{l}\text { Standardised } \\
\text { difference }\end{array}$ & $\begin{array}{l}\text { No arthroplasty } \\
(n=153)\end{array}$ & $\begin{array}{l}\text { Arthroplasty } \\
(n=153)\end{array}$ & $\begin{array}{l}\text { Standardised } \\
\text { difference }\end{array}$ \\
\hline $\begin{array}{l}\text { Median (interquartile range) } \\
\text { age (years) }\end{array}$ & $69(63-77)$ & $70(64-75)$ & 0.08 & $69(62-76)$ & $70(63-75)$ & 0.08 \\
\hline Women & $1174(74.2)$ & $125(72.3)$ & 0.04 & $109(71.2)$ & $109(71.2)$ & 0 \\
\hline $\begin{array}{l}\text { Median (interquartile range) } \\
\text { body mass index }\end{array}$ & $28(25-32)$ & $28(25-32)$ & 0.14 & $28(26-33)$ & $28(25-33)$ & 0.09 \\
\hline $\begin{array}{l}\text { Median (interquartile range) } \\
\text { hip pain }\end{array}$ & $974(61.6)$ & $100(57.8)$ & 0.08 & $89(58.2)$ & $86(56.2)$ & 0.04 \\
\hline $\begin{array}{l}\text { Median (interquartile range) } \\
\text { knee pain }\end{array}$ & $1378(87.1)$ & $153(88.4)$ & 0.04 & $138(90.2)$ & $134(87.6)$ & 0.08 \\
\hline \multicolumn{7}{|l|}{ Living conditions: } \\
\hline Lives alone & $510(32.2)$ & $50(28.9)$ & 0.07 & $49(32.0)$ & $42(27.5)$ & 0.09 \\
\hline Lives with others & $1055(66.7)$ & $123(71.1)$ & 0.09 & $102(66.7)$ & $111(72.5)$ & 0.09 \\
\hline $\begin{array}{l}\text { Lives in long term care } \\
\text { facility }\end{array}$ & $17(1.1)$ & $0(0)$ & 0.11 & & & \\
\hline \multicolumn{7}{|l|}{ Income (\$C): } \\
\hline$>20000$ & $477(30.2)$ & $51(29.5)$ & 0.01 & $43(28.1)$ & $48(31.4)$ & 0.07 \\
\hline$\leq 20000$ & $820(51.8)$ & $86(49.7)$ & 0.04 & $79(51.6)$ & $78(51.0)$ & 0.01 \\
\hline Missing & $285(18.0)$ & $36(20.8)$ & 0.07 & $31(20.3)$ & $27(17.6)$ & 0.07 \\
\hline \multicolumn{7}{|l|}{ Education: } \\
\hline High school or less & $1351(85.4)$ & $140(80.9)$ & 0.13 & $125(81.7)$ & $124(81.0)$ & 0.02 \\
\hline Post-secondary & $231(14.6)$ & $33(19.1)$ & 0.13 & $28(18.3)$ & $29(19.0)$ & 0.02 \\
\hline \multicolumn{7}{|l|}{ Smoker: } \\
\hline Never & $752(48.8)$ & $83(49.4)$ & 0.10 & $75(49.0)$ & $75(49.0)$ & 0.01 \\
\hline Former & $552(35.8)$ & $70(41.7)$ & 0.10 & $62(40.5)$ & $63(41.2)$ & 0.01 \\
\hline Current & $236(15.3)$ & $15(8.9)$ & 0.10 & $16(10.5)$ & $15(9.8)$ & 0.01 \\
\hline NSAID use & $576(36.4)$ & $89(51.4)$ & 0.31 & $84(54.9)$ & $80(52.3)$ & 0.05 \\
\hline \multicolumn{7}{|l|}{ No of comorbidities: } \\
\hline 0 & $72(4.6)$ & $8(4.6)$ & 0.07 & $\leq 5(2.0)$ & $7(4.6)$ & 0.05 \\
\hline 1 & $294(18.6)$ & $42(24.3)$ & 0.07 & $33(21.6)$ & $38(24.8)$ & 0.05 \\
\hline 2 & $502(31.7)$ & $53(30.6)$ & 0.07 & $67(43.8)$ & $47(30.7)$ & 0.05 \\
\hline 3 & $427(27.0)$ & $37(21.4)$ & 0.07 & $31(20.3)$ & $32(20.9)$ & 0.05 \\
\hline$\geq 4$ & $287(18.1)$ & $33(19.1)$ & 0.09 & $19(12.4)$ & $29(19.0)$ & 0.05 \\
\hline $\begin{array}{l}\text { Pre-existing cardiovascular } \\
\text { disease }\end{array}$ & $541(34.2)$ & $47(27.2)$ & 0.15 & $40(26.1)$ & $40(26.1)$ & 0 \\
\hline Diabetes & $249(15.7)$ & $24(13.9)$ & 0.05 & $20(13.1)$ & $22(14.4)$ & 0.04 \\
\hline Depression & $529(33.4)$ & $50(28.9)$ & 0.10 & $53(34.6)$ & $45(29.4)$ & 0.09 \\
\hline Hypertension & $955(60.4)$ & $118(68.2)$ & 0.16 & $97(63.4)$ & $102(66.7)$ & 0.07 \\
\hline $\begin{array}{l}\text { Median (interquartile range) } \\
\text { SF-36 }\end{array}$ & $50(32-67)$ & $55(40-72)$ & 0.22 & $55(37-67)$ & $55(40-72)$ & 0.01 \\
\hline $\begin{array}{l}\text { Median (interquartile range) } \\
\text { WOMAC }\end{array}$ & $41(25-53)$ & $48(33-56)$ & 0.31 & $45(35-53)$ & $48(32-56)$ & 0.01 \\
\hline $\begin{array}{l}\text { Pre-baseline total joint } \\
\text { arthroplasty }\end{array}$ & $150(9.5)$ & $41(23.7)$ & 0.46 & $36(23.5)$ & 35 (22.9) & 0.02 \\
\hline
\end{tabular}

$\$ C 1.00$ (£0.60; $\$ 0.96 ; € 0.71)$.

NSAID=non-steroidal anti-inflammatory drug; SF-36=short form-36 general health survey; WOMAC=Western Ontario and McMaster Universities arthritis index. 
Table 3| Outcomes after propensity score matched landmark analyses

\begin{tabular}{lcccc} 
& & & \multicolumn{2}{c}{ Cardiovascular event } \\
\cline { 4 - 5 } Analysis & Exposure period (years) & No in group & Hazard ratio (95\% Cl) & P value \\
Primary & 3 & 153 & $0.56(0.43$ to 0.74$)$ & $<0.001$ \\
\hline Knee only* & 3 & 94 & $0.46(0.29$ to 0.75$)$ & 0.0017 \\
\hline Hip only $\dagger$ & 3 & 49 & $0.61(0.38$ to 0.99$)$ & 0.0442 \\
\hline Subgroup $\neq$ & 3 & 122 & $0.71(0.53$ to 0.96$)$ & 0.0273 \\
\hline Sensitivity & 2 & 126 & $0.67(0.50$ to 0.90$)$ & 0.0078 \\
\hline Sensitivity & 4 & 179 & $0.57(0.44$ to 0.74$)$ & $<0.001$ \\
\hline
\end{tabular}

*Excluded people who underwent total hip arthroplasty.

†Excluded people who underwent total knee arthroplasty.

$\ddagger$ Analysis done in patients with at least one risk factor for cardiovascular disease (diabetes, hypertension, or pre-existing cardiovascular disease), with an exposure window of three years.

$\S$ Analysis with exposure window of two years.

TAnalysis with exposure window of four years. 


\section{Figures}

A

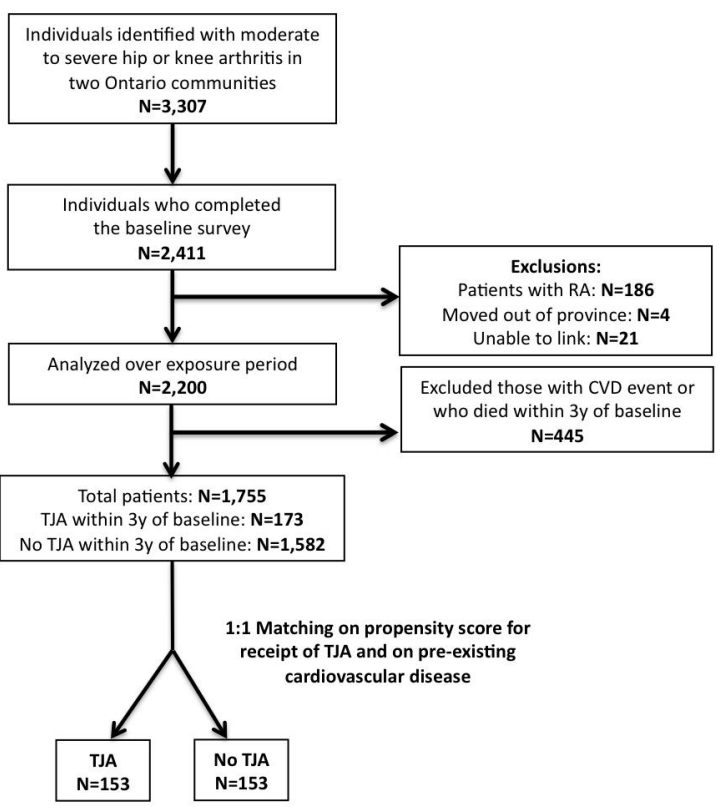

B

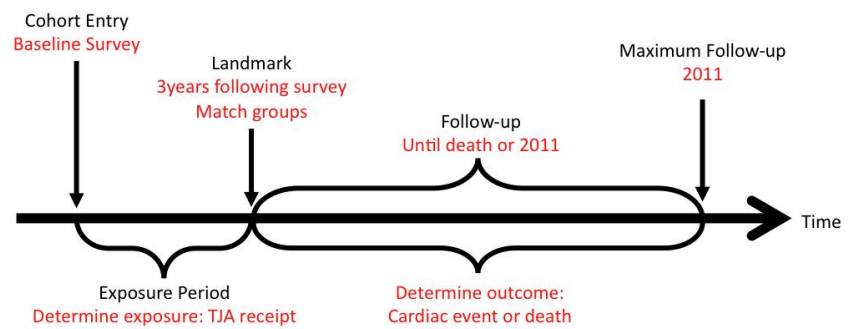

Fig 1 Details of study population and timeline

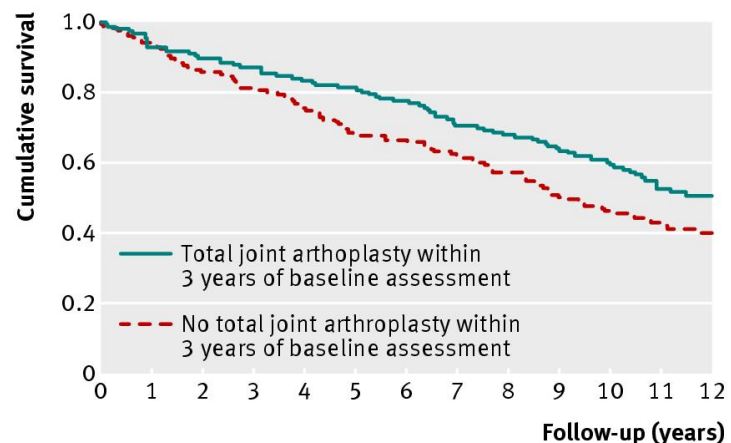

Fig 2 Survival probability for matched groups 